\title{
Memória, história, sociabilidades: um espaço para a geografia brasileira no Rio de Janeiro
}

Luciene Pereira Carris Cardoso*

\begin{abstract}
Resumo
O presente artigo ${ }^{1}$ analisa a contribuição da Sociedade de Geografia do Rio de Janeiro para o reconhecimento do território brasileiro e a promoção do desenvolvimento do saber geográfico no Brasil. A entidade apresentava-se como um espaço de sociabilidade reunindo diversos intelectuais, políticos e cientistas.
\end{abstract}

Palavras-chave: Geografia; Território; História.

\begin{abstract}
The present article analyzes the contribution of the Rio de Janeiro Geographical Society to the acknowledgement of the Brazilian territory and to the spread of geographical acquaintance across the country. This entity played a relevant rule promoting the social reunion of intellectuals, politicians and scientists.
\end{abstract}

Keywords: Geography; Territory; History.

\section{Introdução}

Em 2014, a Sociedade Brasileira de Geografia completou cento e trinta e um anos de existência. A sua trajetória institucional se relaciona com a própria história do Rio de Janeiro. Criado como Município Neutro ou Município da Corte pelo Ato Adicional em 1834, tornouse Distrito Federal republicano (1889-1960); em seguida Estado da Guanabara (1960-1975) e, finalmente, Município do Rio de Janeiro (de 1975 em diante). A construção do Rio de Janeiro como capital nos Oitocentos coincidia com a montagem do Estado imperial centralizado e com a idealização de uma nação "civilizada" nos trópicos. Sede do governo nacional, era na cidade que ecoavam os debates na imprensa, no parlamento e nas diversas instituições existentes (Motta, 2001).

\footnotetext{
* Pós-doutora e pesquisadora associada ao Laboratório de Geografia Política da Universidade de São Paulo, doutora em História, Universidade do Estado do Rio de Janeiro. lucienecarris@hotmail.com

10 trabalho ora apresentado é uma síntese do livro 0 lugar da geografia brasileira: a Sociedade de Geografia do Rio de Janeiro entre 1883-1945, publicado pela editora Annablume em 2013. Trata-se originalmente da dissertação e tese, ambas defendidas no âmbito do Programa de Pós-Graduação em História da Universidade do Estado do Rio de Janeiro. Agradeço a CAPES e FAPERJ pelas bolsas concedidas, respectivamente.
} 
No Rio de Janeiro, se estabeleceram diversas instituições particulares e/ou subvencionadas pelas esferas governamentais com propósitos variados. Muitas delas voltadas para as profissões instituídas no século XIX, tais como engenheiros, médicos e advogados. A participação em várias instituições culturais, científicas e literárias constituía uma prática comum entre os intelectuais oitocentistas. Tais profissionais e muitos funcionários públicos integravam o corpo social dessas entidades, tais como: a Academia de Medicina, o Instituto dos Advogados Brasileiros, o Instituto Politécnico e o Clube de Engenharia, entre outras que foram surgindo ao longo do tempo (Coelho, 1999:96).

Além de associações consideradas específicas de classe, podemos ainda citar entidades do porte do Instituto Histórico e Geográfico Brasileiro (1838), da Seção Filial da Sociedade de Geografia de Lisboa no Brasil (1878) e da Sociedade de Geografia do Rio de Janeiro (1883), antigo nome da atual Sociedade Brasileira de Geografia, a ser examinada no corrente texto. Atualmente localizada no Centro do Rio de Janeiro, dedicou-se desde a sua fundação a diversos temas que englobassem o reconhecimento do território brasileiro, de seus habitantes e de seus recursos naturais. Nela, advogados, médicos, engenheiros militares e outros profissionais liberais se reuniam para debater e promover estudos sobre o espaço geográfico brasileiro, o que pode ser considerado como o primeiro movimento em prol da institucionalização do saber geográfico no Brasil.

O caso brasileiro não foi isolado, se insere no chamado "movimento geográfico" que estimulou a multiplicação de instituições congêneres na Europa e no continente americano que atravessou o século XIX. De um modo geral, as sociedades geográficas estabelecidas no novo continente possuíam características comuns, ou seja, pretendiam divulgar o conhecimento científico, por meio de intercâmbio de publicações, da participação em congressos, das trocas de correspondências congêneres estrangeiras, principalmente europeias. Porém seus objetivos se direcionavam para organização dos espaços nacionais. Assim, semelhantemente às congêneres europeias, também se tornavam instrumentos específicos a serviço do Estado, pois as informações levantadas auxiliavam no reconhecimento do território. Por outro lado, contribuíam para a formação da identidade nacional das ex-colônias, favorecendo o sentimento de pertencimento às nações recém-criadas.

\section{A criação da Sociedade de Geografia: demandas e compromissos entre 1883 e 1945}

A Sociedade de Geografia do Rio de Janeiro foi um dos espaços científicos que desfrutou do patrocínio de ex-imperador D. Pedro II. Originou-se de uma cisão entre os associados da seção filial da Sociedade de Geografia de Lisboa no Rio de Janeiro que funcionou entre 1878 e 1888. Ao que tudo indica, uma orientação nacionalista estava em curso na congênere portuguesa, uma vez que um grupo intencionava nacionalizar a associação, enquanto outro defendia a sua fidelidade ao programa expansionista português. ${ }^{2}$ A Seção se dividiu, e parte dos seus integrantes fundou a Sociedade de Geografia do Rio de Janeiro.

Inspirando-se nos boletins da Sociedade de Geografia de Paris, a congênere brasileira a partir de 1885 deu início à publicidade de seu periódico oficial. O surgimento de seus boletins dedicados ao conhecimento geográfico derivou do movimento colonial em marcha

2 Sobre a história da Seção Filial da Sociedade de Geografia de Lisboa no Brasil, ver Mary (2010). 
nos Oitocentos, um período marcado pelo predomínio do imperialismo econômico, como salientou o historiador Eric Hobsbawm. Aliás, um ligeiro exame dos sumários dos primeiros boletins confirma o interesse da Sociedade de Geografia em descrever os rios que compõem a hidrografia brasileira. Desde a sua criação, empreendeu um programa de trabalho que buscava responder às demandas do governo, por meio de práticas científicas, direcionadas para o melhor conhecimento do espaço físico do Império e de seus habitantes. Tal programa não foi interrompido com o advento do regime republicano, apesar da crise institucional e sociopolítica dos primeiros anos. O seu periódico nos fornece importantes elementos para refletirmos acerca do pensamento da intelectualidade sobre o território brasileiro e a formação de uma identidade nacional.

Nos primeiros anos de funcionamento envolveu-se em diversos projetos, a exemplo da elaboração de uma obra de referência do porte do "Dicionário Geográfico do Brasil" de Alfredo Moreira Pinto em 1884; um plano de criação da Estrada de Ferro Madeira-Mamoré dos engenheiros Júlio Pinkas e Herbert Smith em 1885; a epopeia que envolveu o traslado do meteorito de Bendegó do sul da Bahia para o Museu Nacional em 1887; a Exposição Geográfica Sul-Americana realizada na Escola Politécnica em 1889 com objetivo de comemorar o quinto aniversário da instalação oficial da instituição e que contou com a participação de D. Pedro II e de Conde d'Eu; além das visitas de personalidades estrangeiras, a exemplo do naturalista alemão Karl von den Steinen. Podemos, ainda, destacar a promoção de uma excursão que devassou, em 1888, o norte do Estado do Mato Grosso, realizada por Oscar de Oliveira Miranda, José Carlos da Silva Telles, Augusto Ximeno de Villeroy e Antonio Lourenço da Silva Telles Pires, na qual este último perdeu a vida e, posteriormente, foi homenageado passando a dar nome a um rio na bacia amazônica.

Apesar da queda do regime monárquico em 1889, continuou a cooperar com as autoridades republicanas e a tomar iniciativas objetivando auxiliar o aperfeiçoamento da sociedade, consoante o ideário positivista, e despertar sentimentos cívicos na população. Isso se observa nos temas e problemas abordados nas suas sessões, nos estudos e relatos de experiências, nas homenagens e nas conferências proferidas por sócios e ilustres visitantes estrangeiros, como a do geógrafo anarquista francês Elisée Reclus, que veio ao Brasil, em 1893, levantar informações necessárias para redação do volume dezenove da obra monumental francesa Nouvelle Géographie Universelle da Maison Hachette, dedicada à América Latina.

A Sociedade recebeu outros notáveis viajantes. De passagem pelo Rio de Janeiro, o empresário norte-americano Nathan Appleton, um dos sócios do conde francês Ferdinand de Lesseps, responsável pela criação dos canais de Suez e do Panamá, assistiu a uma das reuniões da Sociedade em $1885 .{ }^{3}$ No ano seguinte, seria realizada uma sessão especial com a presença de D. Pedro II para receber o viajante africano John Augustus Otomba Payne. ${ }^{4}$ Como orador oficial do evento foi escolhido o advogado e educador Joaquim Abílio Borges, defensor da causa abolicionista, que discorreu sobre a vinda dos escravos africanos para o Brasil, o embarque nos navios negreiros até sua chegada e comercialização do lado de cá do Atlântico. ${ }^{5}$ Outra sessão com a presença do monarca consistiu na conferência do ministro

3 SGRJ. Ata da sessão ordinária de 25 de agosto de 1885. Revista da SGRJ, Rio de Janeiro, t. 2, 1886, p. 158.

40 advogado John Augustus Otomba Payne ocupou diversos cargos administrativos na cidade de Lagos, na Nigéria, tais como oficial de Justiça, xerife e secretário do Supremo Tribunal. Dedicou-se, ainda, ao estudo da cultura e da história daquele país, publicando duas obras: Table of principal events in Yoruba history with certain other matters of general interest compiled for use in the courts within the British colony of Lagos (1893) e Payne's Lagos almanac and diary for 1878-1894.

5 SGRJ. Ata da sessão extraordinária de 08 de maio de 1886. Revista da SGRJ, Rio de Janeiro, t. 3, 1887, p. 149. 
da Bolívia João Francisco Velarde, que apresentou um panorama das relações diplomáticas entre a nação boliviana e os demais países vizinhos. ${ }^{6}$

Posteriormente, circulou pelas salas da Sociedade de Geografia o professor de etnologia da Universidade de Gênova e delegado da Sociedade de Geografia de Roma, Vincenzo Grossi, que veio ao Brasil examinar as condições da imigração italiana. ${ }^{7}$ Em 1894, seria a vez dos integrantes da Missão Boliviana Manoel Bollirian, Lisimaco Gutierrez e Ramon Pag, que exploraram uma parte do rio Madeira, entre os limites do Peru, do Madre de Dios e do Alto Acre. ${ }^{8}$ Já em 1899, José Bach pronunciou uma conferência na Sociedade revelando a descoberta de que as sociedades indígenas, ao contrário do que se supunha, possuíam uma origem comum..$^{9}$ Sócio da Royal Geographic Society of London, Bach explorou uma grande parte da América Meridional, desde o Cabo de Horn no Chile até o rio Orinoco na Venezuela, passando pelas fronteiras com o Brasil. Na mesma reunião, a Sociedade recebeu outro viajante, tratava-se do chileno José Rodriguez Martinez que realizava a ousada empreitada de dar a volta ao mundo à pé. ${ }^{10}$

Em 1897, em sessão conjunta realizada com o Instituto Histórico, a Sociedade recebeu a comissão científica belga liderada por Adrien de Gerlache de Gomery que pretendia explorar o Polo Sul. ${ }^{11}$ Já em 1903, o austríaco Barão Ernst von Hesse-Wartegg apresentou um panorama geral da sociedade chinesa. ${ }^{12}$ No ano seguinte, Milfredo Laurel, Gino Cappagli e Emílio Brombrilla planejavam uma viagem para a cidade norte-americana de Saint Louis. Pretendiam visitar a Exposição Universal que seria realizada naquela cidade. Para tanto, foram mais de uma vez à Sociedade com o intuito de coletar informações em seu acervo e traçar o melhor percurso. ${ }^{13}$

Personalidades femininas também começaram a se fazer presentes na instituição, que, entre outras, recebeu a visita da educadora e médica de origem belga Marie Rennote Robinson Wright. Ela doou, em 1903, sua obra The New Brazil, com várias ilustrações e fotografias da cidade de São Paulo da virada do século. ${ }^{14}$ Marie Rennote se destacou no cenário cultural e científico paulistano, sendo considerada por muitos estudiosos a renovação da educação em seu país. ${ }^{15}$

6 SGRJ. Ata da sessão extraordinária de 23 de junho de 1886. Revista da SGRJ, Rio de Janeiro, t. 3, 1887, p. 153.

7 SGRJ. Ata da sessão ordinária de 19 de setembro de 1891. Revista da SGRJ, Rio de Janeiro, t. 8-9, 1892-1893, p. 203.

8 SGRJ. Ata da sessão ordinária de 20 de dezembro de 1894. Revista da SGRJ, Rio de Janeiro, t. 11, 1896, p. 105.

9 SGRJ. Ata da sessão ordinária de 08 de julho de 1899. Revista da SGRJ, Rio de Janeiro, t. 15, 1912, p. 50.

10 Idem, p. 51.

11 SGRJ. Ata da sessão ordinária de 23 de dezembro de 1897. Revista da SGRJ, Rio de Janeiro, t. 15, 1902, p. 16.

12 SGRJ. Ata sessão de 22 de junho de 1903". Revista da SGRJ, Rio de Janeiro, t. 18, 1915, p. 37.0 viajante austríaco já havia visitado diversos lugares do mundo, inclusive o Japão e a China, os Estados Unidos e alguns países da América do Sul. 0 volume citado era dedicado ao Brasil e aos países da Bacia do Prata, pois estas áreas apresentavam maiores vantagens econômicas para a introdução de colonos alemães. Von Hesse, excursionou pelo continente por três vezes entre os anos de 1903 e 1913 e, na sua opinião, a região era promissora para os futuros colonos.

13 SGRJ. Ata da sessão ordinária de 16 de abril de 1904. Revista da SGRJ, Rio de Janeiro, t. 15, 1902, p. 48.

14 SGRJ. Ata da sessão de 05 de dezembro de 1903. Revista da SGRJ, Rio de Janeiro, t. 18, 1915, p. 40.

15 Professora formada, aos quarenta anos de idade completou o curso de Medicina na prestigiada Woman's Medical College of Pennsylvania, especializando-se na área de ginecologia e obstetrícia. Em 1895, conseguiu validar o seu diploma de médica no Brasil, defendendo a tese "Influência da educação da mulher sobre a medicina social", perante uma banca organizada pela cadeira de Higiene e Mesologia da Faculdade de Medicina e de Farmácia do Rio de Janeiro, chefiada por Benjamin Antônio da Rocha Faria. 
Já em 1914, após a gestão de Francisco Marcondes Homem de Mello, ${ }^{16}$ o barão Homem de Mello, após o falecimento de seu primeiro presidente José Lustosa da Cunha Paranaguá, o Marquês de Paranaguá, inaugurou-se uma nova fase na Sociedade de Geografia do Rio de Janeiro. O período caracterizou-se pela sucessão de militares na presidência do grêmio, a partir do Marechal Gregório Thaumaturgo de Azevedo. Aliás, desde a fundação, sempre foi notória a presença de representantes das Forças Armadas nos quadros da Sociedade, o que não é de estranhar. Para esses militares, conforme assinalou Nelson Werneck Sodré, a geografia constituía um elemento fundamental na defesa da soberania nacional, a qual se resumia na: “(...) missão de manter a base física herdada da fase colonial e de assegurar o exercício da autoridade central em toda a extensão daquela extensa base física” (Sodré, 1968:229).

Mas a participação de oficiais do Exército e da Marinha nas sessões da Sociedade ganharia novos contornos, devido ao contexto da Primeira Guerra Mundial. A proporção tomada pelo conflito europeu suscitou interesse crescente pela confecção de mapas e de outras formas de representação espacial, uma vez que a maioria das reivindicações políticas sobre territórios nacionais assentava-se em argumentos históricos (Black, 2005:175-179). Basta lembrar que, em 1916, o sueco Johan Rudolf Kjellén (1864-1922), no livro O Estado como forma política, inspirado nas ideias de Friderich Ratzel, formulou as bases de uma nova disciplina, denominada "geopolítica”, fundamentado em noções da História e da Geografia, sob a justificativa de que: “(...) o anseio de conquistar o território era a dimensão crucial da busca pela sobrevivência empreendida por uma nação ou por um estado (Black, 2005:175). Para Kjellén, o Estado deveria constituir um organismo sujeito às leis do crescimento, cujo território poderia ser ampliado através da colonização ou da ocupação de áreas lindeiras (Miyamoto, 1995:27). ${ }^{17}$ Segundo o historiador Eric Hobsbawn, o período entre as duas guerras mundiais teve importância decisiva na construção do pensamento geopolítico, não apenas na Alemanha, como igualmente na França, Grã-Bretanha e Estados Unidos. Pois, até 1914, o mundo não conhecera guerras mundiais, nem jamais presenciara tamanha mobilização de recursos, materiais ou não, para amparar os esforços de guerra (Hobsbawn, 1995).

No Brasil, desde o final do século XIX, as autoridades republicanas preocupavamse com a soberania e a preservação do espaço nacional. Se, por um lado, a vasta extensão territorial era motivo de ufanismo, por outro, o isolamento de algumas regióes, afastadas dos grandes centros e situadas em faixas de fronteira, daria ensejo a diversos projetos de integração do território (Cf. Martins Junior, 2001:95). Paralelamente, o governo passou a conferir maior importância à atuação de entidades como a Sociedade de Geografia do Rio de Janeiro, reconhecida como órgão de utilidade pública, por decreto assinado pelo presidente Wenceslau Braz Pereira Gomes. ${ }^{18}$

16 Sobre Francisco Inácio Homem de Mello, ver IHGB. Dicionário biobibliográfico de historiadores, geógrafos e antropólogos brasileiros; sócios falecidos entre 1881/1920; preparado por Vicente Tapajós com a colaboração de Pedro Tórtima (Rio de Janeiro: 0 Instituto, 1993, p. 85). Bacharel em direito, político, historiador e cartógrafo consagrado, autor do Atlas do Brasil, publicado 1909, com a colaboração de Beaurepaire Rohan. Deixou expressiva obra no campo da Geografia, influenciando diversos estudiosos, a exemplo de Carlos Delgado de Carvalho. Cf. Cavenaghi, 2006:204.

17 Convém destacar uma distinção entre a Geografia Política e a Geopolítica. Ambas se diferem quanto ao objeto de investigação e pertencem a áreas distintas. A primeira refere-se ao campo da Geografia e a segunda relaciona-se à Ciência Política. Segundo William Vesentini, a primeira seria estática como uma fotografia, apoia-se em observações dos fatores geográficos. A Geopolítica, dinâmica como um filme, é essencialmente diligente. Constitui uma teoria de poder apoiada no território, utilizando-se dos fatores geográficos para formular sua política, submete-se a uma ideologia estratégica e militar de dominação.

18 "Decreto n. 3440, de 27 de dezembro de 1917. Reconhece a utilidade pública a Sociedade de Geografia do Rio de Janeiro, o presidente da República dos Estados Unidos do Brasil: Faço saber que o Congresso Nacional decretou e eu sanciono a resolução seguinte: Artigo único: Fica reconhecida de utilidade pública a Sociedade de Geografia do Rio de Janeiro, revogadas as disposições em contrário. Rio de Janeiro, 27 de dezembro 
A problemática da Grande Guerra seria um dos tópicos constantes das reuniões da Sociedade. Na ocasião, o escritor e jornalista Lindolfo Octávio Xavier ofereceu uma síntese do cenário político internacional e advertiu que a guerra refletia a busca alemã pelo predomínio geopolítico mundial. Para ele, embora o Brasil não dispusesse de tecnologia bélica expressiva, em contrapartida, possuía fartura de matérias-primas, como o manganês, o ouro, a borracha e o ferro, além de gêneros (açúcar, café, cacau, algodão, carne bovina), indispensáveis ao abastecimento dos países aliados. Afora esses produtos, o governo do presidente Wenceslau Braz enviou ao teatro de operações grupamentos de pilotos e de médicos militares, navios de guerra e cedeu algumas bases navais. A participação brasileira significava o "triunfo da latinidade", prenunciando o "destino largo e complexo" que estaria reservado à Terra de Santa Cruz no rol das nações civilizadas. ${ }^{19}$

Tempos depois, no mesmo ano em que Candido Mariano da Silva Rondon recebeu a patente de General, a Sociedade de Geografia do Rio de Janeiro realizou uma sessão magna em sua homenagem no Teatro Municipal, no dia 12 de outubro de 1919. Figura emblemática da integração nacional, as missões do general privilegiaram áreas insondadas do território mato-grossense. ${ }^{20}$ Entre 1907 e 1915, foi incumbido de implantar linhas telegráficas no noroeste do Brasil, projeto que se estendeu até o Estado do Amazonas. No período de 19151919, permaneceu naquela região completando explorações de rios, a fim de reunir dados para a "Carta geográfica do Estado de Mato Grosso".

A atuação de Rondon permitira integrar o sertão ao restante da nação brasileira. Sua concepção de nação baseava-se na doutrina positivista, segundo a qual o progresso tecnológico - neste caso o telégrafo - levaria a civilização àquelas comunidades longínquas (Diacon, 1996:12-13). Para a Sociedade, a epopeia de Rondon fechava o ciclo da "geografia heróica” no Brasil: permitiu a incorporação de várias áreas inóspitas e incógnitas, recortadas por rios que escoariam as mercadorias até o Oceano Atlântico, lançando: “(...) bases seguras para o viajante, para o explorador e para o cientista que quiser visitar, trabalhar, estudar naquelas paragens ermas, não sentindo mais em torno de si o vazio que entibia e aniquila" (Diacon, 1996:09). Se, por um lado, a vasta extensão territorial foi motivo de ufanismo, por outro, o isolamento de algumas regiões, afastadas dos grandes centros e situadas em faixas de fronteira, daria ensejo a diversos projetos de integração do território, a exemplo da Comissão de Construção das Linhas Telegráficas, formada por militares, que interligou as comunicações entre Rio de Janeiro, São Paulo e Triângulo Mineiro à Amazônia. Paralelamente, o governo passou a conferir maior importância à atuação de entidades como a Sociedade de Geografia do Rio de Janeiro, reconhecida como órgão de utilidade pública, por decreto assinado pelo presidente Wenceslau Braz Pereira Gomes em 1917.

Coerente com os movimentos culturais de cariz nacionalista no Brasil nas primeiras décadas do século XX, a instituição empenhou-se na promoção de atividades acadêmicas e na publicação de obras voltadas para despertar sentimentos cívicos, que buscavam descortinar

de 1917, $96^{\circ}$ da Independência e $29^{\circ}$ da República. Wenceslau Braz P. Gomes, Carlos Maximiliano Pereira dos Santos" (Revista da SGRJ, Rio de Janeiro, t. 19-20-21, 1918, p. 5-11). Apesar de tal reconhecimento, em 1922, foi publicado um único volume da revista que corresponde ao período 1912-1922. Entretanto, as atas e os relatórios não foram editados e nenhuma menção foi registrada sobre essa falta. Apesar do Decreto de 1917 garantir a impressão gratuita dos boletins e das revistas, esse volume foi impresso pela Tipografia do Instituto Muniz Barreto. A comissão da redação era presidida por Manoel Cícero Peregrino da Silva, como secretários Lindolfo Xavier, Álvaro Bittencourt Berford e Francelino Wandeck.

19 Idem, p. 55

20 Para se ter uma ideia da dimensão dos seus trabalhos, no período de 1890 a 1898, Rondon chefiou a comissão da construção da linha telegráfica entre Goiás e Cuiabá, em seguida as cidades de Cuiabá e Corumbá (1900-1904) e 0 extremo sudoeste do Brasil, chegando às fronteiras do Paraguai e da Bolívia (1905-1906). 
o país aos brasileiros, a exemplo da Geografia do Centenário (1922) e do Curso Superior Livre de Geografia (1926-1927). A passagem do Centenário da Independência provocaria grande mobilização nas esferas letradas do Rio de Janeiro. Examinar os cem anos do Estado brasileiro, em primeiro lugar, implicava romper com padrões estrangeiros e privilegiar ideias essencialmente nacionais. Acrescente-se a isso a turbulência política pela qual o país passava, fruto dos problemas gerados pela crise do pacto político das oligarquias e da descrença dos valores da Belle Époque. Esses elementos impulsionaram o surgimento de uma análise crítica que sublinhava a afinidade entre território e Nação, na qual a Geografia passou a desempenhar uma das principais ferramentas de reflexão sobre a nacionalidade (Motta, 1994:06).

A Geografia do Centenário havia sido planejada para alcançar dez volumes, mas apenas dois volumes foram impressos. Estimava-se, ainda, contar com a colaboração de estudiosos que não fossem vinculados aos quadros da Sociedade de Geografia, "um conjunto de personalidades representativas do cenário da época". O livro monumental deveria ser fartamente ilustrado e acrescido de um mapa atualizado do Brasil, especialmente encomendado à Comissão da Carta Geográfica Comemorativa do Centenário. Dirigida ao grande público, a coleção de pretendia, didaticamente, descortinar o Brasil aos brasileiros. Seguiram-se outros projetos de cunho pedagógico, como o Curso Superior Livre de Geografia, que funcionou entre os anos de 1926 e 1927, destinado à atualização de professores primários, organizado por um corpo de especialistas de escol, que reuniu nomes como Fernando Raja Gabaglia, Everardo Backheuser e Delgado de Carvalho. O projeto pedagógico do Curso pretendia inserir uma nova concepção de Geografia na Sociedade, combinando as ideias de Friedrich Ratzel (18441904) com as de Vidal de La Blache (1845-1918). ${ }^{21}$

Além disso, a Sociedade de Geografia do Rio de Janeiro empenhou-se na realização de atividades acadêmicas, na divulgação de trabalhos e na publicação de textos inéditos, que lançavam luz sobre aspectos ainda não revelados do território e da população brasileira. Neste sentido, tornou-se um espaço de discussão, recebendo estudiosos como o engenheiro Vicente Licínio Cardoso, então redator-chefe da Revista da Sociedade. Em duas ocasiões, ele apresentou uma síntese das suas investigações sobre o rio São Francisco, assunto que há muito o instigava, apesar de pouco privilegiado pelos estudiosos de então. Acentuava que apesar da sua comprovada importância, a região atravessada pelo São Francisco permanecia obscura para a maioria dos brasileiros, no seu entender: “(...) a ignorância do presente daquele vale exprime e exemplifica, ao mesmo tempo, esse perigo largo em que temos incorrido tantas vezes, vivendo no litoral, mas pensando, de contínuo, como se a nossa cabeça estivesse...na própria Europa" (Cardoso, 1925:38).

A partir dos anos 1930, significativas transformações afetaram a vida política, econômica, social e cultural da Nação, tais mudanças já se prenunciavam na década anterior, marcada pela crise do sistema oligárquico, a emergência do movimento tenentista, a comemoração do Centenário da Independência do Brasil e a realização da Semana de Arte Moderna em 1922. Ao mesmo tempo, as consequências da Primeira Guerra Mundial indicavam que o ideal cosmopolita cedia lugar a passos largos ao nacionalismo exacerbado. A busca pelas

210 empreendimento pedagógico da Sociedade de Geografia do Rio de Janeiro reuniu figuras expressivas, recrutadas não apenas entre os membros da instituição, mas também em outras entidades, como a Escola Politécnica do Rio de Janeiro, o Colégio Pedro Il, a Escola Normal e o Museu Nacional, tais como: Edgar Sussekind de Mendonça, Honório de Sousa Silvestre, Luiz Caetano de Oliveira, Heloísa Alberto Torres, Luis Caetano de Oliveira, Abel Pinto, Jorge Machado e Roberto Freire Seidl. 
raízes brasileiras constituiria, assim, uma das principais preocupações dos homens públicos e letrados da época: “(...) seja através dos ideais da ciência ou da racionalidade (geração de 1870) da arte ou da intuição (geração de 1920), imbuídos de vocação messiânica, senso de missão ou dever social, os intelectuais se autoelegeram sucessivamente consciência iluminada do nacional" (Velloso, 2003:148).

Aliás, o golpe de Estado que pôs fim à Primeira República, em 1930, não afetou o funcionamento da SGRJ. Desde o primeiro momento, a Sociedade mostrou-se favorável ao movimento que deu início à chamada Era Vargas, o que não é de estranhar, uma vez que por lá transitavam figuras que apoiaram a Aliança Liberal, a exemplo de Raul Tavares, Bernardino José de Sousa, Emílio Fernandes de Sousa Doca, Luiz Alves de Oliveira Belo, Liberato Bittencourt, Mário Augusto Teixeira de Freitas, José Matoso Maia Forte, Alexandre Emilio Sommier, Francisco Jaguaribe Gomes de Matos e Thiers Fleming. A Sociedade de Geografia, aliás, não se mostraria indiferente a essas questões políticas. Em que pesem as reiteradas manifestações de seus filiados sobre a neutralidade da ciência, o reduto científico revelou-se simpático ao movimento que pôs fim à Primeira República (Pimentel, 1935:60$61)$.

A associação carioca, entre outros temas que mais tarde seriam objeto da atenção do governo, empenhou-se em examinar a questão do reordenamento geopolítico do território brasileiro, a exemplo da "Grande Comissão Nacional de Redivisão Territorial e Localização da Capital Federal”, coordenada por Everardo Backheuser, então vice-presidente da Sociedade de Geografia. O projeto deveria somar esforços para “(...) servir bem, sem o menor laivo e preocupação subalterna ou regionalista, os supremos interesses do Brasil”. ${ }^{22}$ No fundo, buscava-se diminuir o poder das unidades mais expressivas da Federação, a propósito de promover o equilíbrio entre os estados.

Previa a adoção de um quadro geopolítico menos fragmentado, formado de vinte unidades federativas e dez territórios lindeiros, cobrindo praticamente toda a área de fronteira com as nações vizinhas, entre o extremo norte e o sudoeste do país, o que revela forte preocupação com a defesa da soberania nacional. Sugeria, ainda, substituir a denominação de "estado" pela de "província”, de acordo com a tradição histórica da autonomia política nacional. Para legitimar tais alterações, a Comissão advertia para necessidade de se realizar uma campanha de esclarecimento junto à população, de forma a conscientizá-la da sua importância. Por sinal, algumas das sugestões oferecidas pela Grande Comissão apareceriam incorporadas ao novo mapa político brasileiro de 1943. Além do projeto encabeçado pela Sociedade, ocorreram iniciativas individuais de alguns associados, como Everardo Backheuser, Raul Bandeira de Mello e Ezequiel Ubatuba.

Outros trabalhos voltaram-se para a ocupação dos espaços vazios do interior do país e a discussão da problemática da imigração. Os associados Raimundo Saladino de Gusmão, José Wanderley de Araújo Pinho, João Ribeiro Mendes e José Magarinos não viam com bons olhos a introdução do imigrante japonês. Considerava-se aceitável o seu ingresso no país, desde que direcionado exclusivamente para o povoamento de áreas inóspitas. Ponderavase que a "arianização" da população brasileira, sobretudo por meio do elemento europeu, era primordial para o desenvolvimento econômico. José Wanderley de Araújo Pinho, por exemplo, alegava que a dificuldade de assentamento dos imigrantes oriundos do Velho

22 SGRJ, “Grande Comissão Nacional de Redivisão Territorial e Localização da Capital Federal”. Revista da Sociedade, Rio de Janeiro, t. 37, 1933, p.71. 
Mundo não deveria ser atribuída tão somente a fatores climáticos, mas à ausência de um planejamento oficial que determinasse a localização, a organização e a manutenção das colônias. Justificava, deste modo, o anteprojeto que ele apresentara à Câmara dos Deputados, ao passo que visava direcionar o elemento japonês para os estados do Norte e do Nordeste, proibindo sua fixação nas colônias já existentes e indicando a instalação de quartéis do Exército nesses mesmos núcleos (Pinho, 1935). De fato, a política de povoamento implementada por Getúlio Vargas evitou o estabelecimento de imigrantes nas cidades, procurando assentá-los, prioritariamente, nas áreas de fronteira do extremo Oeste (Gomes, 1982:162).

A implementação de políticas públicas buscava articular iniciativas científicas com a conformação de uma cultura política, na qual a temática do território nacional, a exploração racional dos seus recursos naturais e sua ocupação ordenada ganhariam um espaço singular. Estabeleceu-se, assim, uma espécie de via de mão dupla entre os órgãos federais que reconheciam a contribuição do tradicional reduto, recebendo em troca apoio e colaboração na implementação dos seus programas de trabalho. Não houve, portanto, inicialmente, um conflito de interesses entre a "associação de diletantes" e os organismos que seriam criados ao longo aos anos 1930, ou querelas, uma vez que o sistema geográfico instituído em 1938 integrava antigos e modernos.

A experiência da Sociedade haveria de ser valorizada e seus associados desempenhariam papéis de primeira grandeza. Destaquem-se nomes como Everardo Backheuser, Carlos Delgado de Carvalho, Fernando Raja Gabaglia e Mario Augusto Teixeira de Freitas. Deste modo, apesar de instituição de caráter privado, foi integrada ao sistema geográfico oficial do Instituto Brasileiro de Geografia e Estatística, estabelecido por Vargas, em 1938, o que estreitaria ainda mais a sua colaboração com os órgãos federais, inclusive, as recém-criadas faculdades de Filosofia.

Em 1931, por indicação do Governo Provisório e com o seu patrocínio, a Sociedade de Geografia participou do Terceiro Congresso Internacional de Geografia em Paris, quando se estabeleceu o primeiro contato com a União Geográfica Internacional (UGI). ${ }^{23}$ Como representante da SGRJ, foi enviado o sócio Alberto José de Sampaio, membro da Academia Brasileira de Ciências, professor de Botânica do Museu Nacional, antigo integrante da Comissão Rondon e reconhecido especialista na flora mato-grossense (Franco; Drummond, 2005:153). Ao retornar ao Brasil, Sampaio assinalava que o país fora convidado a se filiar à União Geográfica Internacional pelo professor Emmanuel De Martonne, secretário-geral daquele evento e diretor do Instituto de Geografia da Universidade de Paris (Sampaio, 1931:202). Em 25 de julho de 1933, em sessão conjunta da Sociedade de Geografia do Rio de Janeiro, do Instituto Histórico e Geográfico Brasileiro e da Academia Brasileira de Ciências, De Martonne recebeu o título de membro honorário da Sociedade. Naquela oportunidade, sugeriu a entrada do país na UGI (De Martonne, 1934:41). De fato, o ingresso do Brasil naquele organismo suscitou imensa atividade que culminou num movimento de renovação da disciplina com a vinda de professores franceses, a criação das Universidades de São Paulo e do Distrito Federal, bem como o estabelecimento de um organismo oficial de coordenação e de sistematização dos conhecimentos geográficos e estatísticos sobre o território nacional, o Instituto Brasileiro de Geografia e Estatística.

23 A entidade fora criada em 1922 na Bélgica, com o propósito de incentivar o estudo dos problemas geográficos; iniciar e coordenar investigações geográficas que requeriam a cooperação internacional, por meio da discussão científica e da publicação de obras, incitar a padronização e a compatibilidade de métodos, nomenclaturas e simbologias empregadas na geografia e promover encontros internacionais a cada três anos. $01^{\circ}$ Congresso Internacional de Geografia realizou-se no Egito, em 1925, e $02^{\circ}$ na Inglaterra, em 1928. 
Seja como for, a instituição assumiu ainda a vanguarda da convocação dos congressos brasileiros de Geografia entre 1909 e 1944. O estudo dessas reuniões científicas revelou não apenas a preocupação com o estado da arte ou a evolução da disciplina. Eles constituem um bom termômetro para a avaliação das transformações que se operavam no país, nos âmbitos social, econômico e político. Os certames realizados entre os anos de 1909 e 1926 tiveram lugar em diversas capitais brasileiras, contaram com financiamento de órgãos públicos e maior participação de entidades estaduais que os acolhiam, dando margem ao acentuado aparecimento de contribuições que privilegiavam temáticas locais.

Em 1940, a Sociedade retomou a prática de promover reuniões periódicas da disciplina, interrompida em 1926. De acordo com as Resoluções $n^{\text {os }} 42$ e 48, respectivamente, de 7 de julho e de 30 de outubro de 1939, do Conselho Nacional de Geografia, “(...) a Sociedade de Geografia do Rio de Janeiro e o Instituto Brasileiro de Geografia eEstatística, num entendimento cívico, deliberaram reiniciar a série dos Congressos Brasileiros de Geografia, realizando-os trienalmente.$^{24}$ Cabe distinguir que as jornadas de 1940 e de 1944, cuja programação atendia às demandas do Estado Novo, evidenciam, ainda, a predominância de um saber geográfico de caráter pragmático e utilitário, direcionado para o reconhecimento do espaço nacional e para subsidiar a ação governo de Getúlio Vargas. Por conseguinte, não é de estranhar a sua dimensão política. Porém, isto não significa afirmar que sua contribuição ao conhecimento geográfico deva ser minimizada. Como atestam as discussões travadas, sobretudo na reunião de 1944, é importante assinalar que o campo da Geografia no Brasil já se encontrava em franca delimitação. Não por acaso, se pleiteava a sua separação da História nos cursos das faculdades de Filosofia. Para além disso, despontava a preocupação em definir um perfil para o geógrafo profissional, cuja formação se presumia diferente daquela destinada aos docentes de ensino médio.

Os dois congressos realizados durante o Estado Novo reforçaram a visibilidade da Sociedade de Geografia do Rio de Janeiro. Como integrante do sistema geográfico, as atividades e iniciativas da associação carioca seriam divulgadas na seção "Noticiário", da Revista do IBGE. A par disso, outros fatores contribuíram para lhe granjear maior prestígio. Ao longo da década de 1930, a Sociedade passou por uma fase de rejuvenescimento, com a incorporação de novos filiados, na maior parte, funcionários do IBGE e professores que atuavam nas recém-criadas faculdades de Filosofia, além de militares e políticos, categorias que tradicionalmente frequentavam a SGRJ, desde a sua fundação.

Neste processo de renovação, assumiria um papel de vanguarda nas relações de gênero, ao abrir os seus quadros sociais para o sexo feminino. Para se ter uma ideia, em 1944, ingressaram sete sócias, inclusive, a professora Maria da Conceição Vicente de Carvalho, ${ }^{25}$ umas das pioneiras a defender tese de doutorado na Universidade de São Paulo, sob a orientação de Pierre Monbeig, naquele mesmo ano. ${ }^{26}$ Mas a instituição ainda se beneficiaria da proteção que desfrutava de homens públicos como os ministros José Matoso Maia Forte, Oswaldo Aranha e o ex-chanceler José Carlos Macedo Soares, este último alçado à condição de presidente honorário em 1940. Por sinal, ao receber a deferência, o embaixador vislumbrou

24 Cf. Conselho Nacional de Geografia. "Resolução nº 22, de 18 de julho de 1838”. Revista Brasileira de Geografia. Rio de Janeiro: IBGE, v. 1, no 3, p. 143, jul. set. de 1939. Ver, também, SGRJ. Anais do $9^{\circ}$ Congresso Brasileiro de Geografia, Rio de Janeiro, Serviço Gráfico do IBGE, vol. 1, 1941 , p. 64.

25 Além de Maria da Conceição, em 1944, foram admitidas as seguintes sócias: Iolanda Rabelo de Sousa Ferreira, Judite Valadares Salgado, Maria de Lourdes Jovita, Julieta de Aragão Silveira, Isa Adonias e Isabel D' Aartayette Dias.

26 Ver, SBG, "Relatório das atividades da Sociedade durante o ano de 1945". Revista da SBG, Rio de Janeiro, t. 53, 1946, p. 130 e p. 139. 
a possibilidade do reduto científico comemorar o seu $60^{\circ}$ aniversário de fundação no prédio que idealizara construir para acolher as instituições técnicas e culturais do país, denominado de Palácio do Silogeu Brasileiro.

O decreto-lei 2326 de 10 de junho de 1940 determinava a centralização de sedes de diversos órgãos técnicos e culturais, com a criação de um edifício, no espaço onde já se encontrava o IHGB, na Avenida Augusto Severo. A "Casa do Brasil”, como também era chamada, reuniria a SGRJ, o IBGE, o IHGB, o DASP, o DIP, o INEP, a Liga da Defesa Nacional, a Academia Nacional de Medicina, a Associação Brasileira de Educação, o Instituto da Ordem dos Advogados, além de instituições que desenvolviam atividades ligadas aos serviços de estatística subordinados aos Ministérios da Justiça, da Fazenda, da Agricultura, do Trabalho, da Previdência, da Educação e Saúde, e da Viação. Previa-se, ainda, a criação do Planetário Cruzeiro Sul com objetivos de "recreio e de educação popular". ${ }^{27}$

Animada com o impulso dos últimos tempos, no final de 1944, a Sociedade elegeu uma nova diretoria para o biênio seguinte, encabeçada pelo ex-chanceler José Carlos Macedo Soares, cabendo a vice-presidência ao ministro João Severiano da Fonseca Hermes. Para os postos de segundo e terceiro vice-presidentes foram escolhidos Jorge Dodsworth Martins e Everardo Backheuser, respectivamente. As funções de secretário-geral ficariam a cargo de Mário Campos Rodrigues de Sousa e as de primeiro e segundo secretários por Frederico Augusto Rondon e Silvio Fróis de Abreu. Por sua vez, Luís Alves de Oliveira Belo assumiu as atribuições de tesoureiro e Francisco de Sousa Brasil foi designado orador oficial. A escolha de Macedo Soares para o cargo da presidência não foi aleatória. Macedo Soares já ocupava a direção de outras entidades, por exemplo, do Instituto Histórico e Geográfico Brasileiro (1939-1968), do Instituto Brasileiro de Geografia Estatística (1936-1951 e 1955-1956) e do Instituto Pan-Americano de Geografia e História (1944-1949), ${ }^{28}$ além de haver exercido a presidência da Academia Brasileira de Letras (1942-1943). O ex-chanceler era um homem de governo, possuía excelentes relações com o Palácio do Catete, o que poderia facilitar o livre trânsito da Sociedade nas esferas de poder, iluminando-a publicamente (Martins Filho, 1968:47). A posse de José Carlos de Macedo Soares parecia cercada por bons augúrios.

Assim, estimulada pelos novos rumos que ganhava, a Sociedade participou da organização dos "Cursos de aperfeiçoamento para professores de Geografia do ciclo secundário”, entre 21 e 30 de junho de 1945. Os cursos foram planejados e desenvolvidos em parceria com o Conselho Nacional de Geografia, com a aprovação pelo Ministério da Educação, de acordo com a Lei Orgânica do Ensino Secundário, a Reforma Capanema, promulgada em 1942. Vinha de longe a preocupação da Sociedade com o magistério. Se, em 1926, promoveu cursos para melhorar a qualidade dos professores de ensino primário, consoante a Reforma Capanema, voltou-se para o aprimoramento dos professores de ensino médio. O diploma conferido aos concluintes era reconhecido como título para admissão no "segundo ciclo de extensão de professorado".

27 Cf. Freitas, Mário Augusto Teixeira de, "Carta de (...) aos jornais do Brasil sobre a Construção do Silogeu Brasileiro, 13 de julho de 1940 ". Arquivo Nacional, Coleção Mário Augusto Teixeira de Freitas, SG.D/1.828; Ver também, “Decreto-Lei n. 2326 de 10 de junho de 1940 ”. Revista Brasileira de Geografia, Rio de Janeiro, Instituto Brasileiro de Geografia e Estatística, v. 2, n.3, jul./set., 1940, p. 504.

28 Vale acrescentar que Macedo Soares também participou de outras associações científicas e culturais brasileiras e estrangeiras: Academia Internacional de Diplomacia, Ordem dos Advogados de São Paulo, Sociedade Brasileira de Antropologia e Etnografia, Liceu Literário Português, Academia Brasileira de Filologia e Academia Paulista de Letras, Instituto Histórico y Geográfico del Uruguai, Academia Uruguaya de Letras, Academia Argentina de Letras, Academia das Ciências de Lisboa, Real Academia de História de Portugal e Sociedade de Geografia de Lisboa, entre outras. 
Sem dúvida, na preparação do programa, pesou a experiência pioneira desenvolvida pela Sociedade de Geografia, na década de 1920, uma vez que o corpo docente seria capitaneado pelos mesmos Everardo Backheuser, Fernando Antonio Raja Gabaglia e Carlos Delgado de Carvalho. A esses nomes uniram-se os técnicos do Instituto Brasileiro de Geografia e Estatística, Jorge Dodsworth Martins, Jorge Zarur, J. C. Junqueira Schmidt, João Capistrano Raja Gabaglia, Alírio de Matos, Cristóvão Leite de Castro, e os estrangeiros Giorgio Mortara e o Francis Ruellan. Participaram da cerimônia inaugural do curso o presidente da Sociedade, José Carlos Macedo Soares, a professora Lúcia Magalhães, diretora da Divisão do Ensino Secundário, e o engenheiro Cristóvão Leite de Castro, secretário-geral do Conselho Nacional de Geografia, além do corpo de professores e alunos. ${ }^{29}$

Impulsionado pelos sucessos recentes, iniciou-se na Sociedade um movimento em prol da reforma dos seus estatutos. Diga-se de passagem, desde a fundação, seus diplomas legais sofreriam apenas ligeiros acréscimos, mas nada que afetasse a estrutura básica fixada em 1883. ${ }^{30}$ Os novos estatutos definiam os fins da entidade; a formação dos seus quadros sociais; a composição da diretoria e do conselho diretor, das assembleias ordinárias e extraordinárias; e dispunham sobre a estrutura e o funcionamento, deliberando que o reduto científico seria dissolvido, caso o cadastro social atingisse menos de dez membros, devendo o seu patrimônio ser incorporado ao Instituto Histórico e Geográfico Brasileiro. Introduziram, ainda, uma mudança decisiva: deliberavam o fim do nome de Sociedade de Geografia do Rio de Janeiro. Substituíam-na por uma entidade de âmbito nacional, com a denominação de Sociedade Brasileira de Geografia, com intuito de ampliar o seu espectro de atuação no sistema geográfico.

De todo modo, observa-se que, desde a fundação, em 1883, a Sociedade de Geografia reuniu indivíduos que se destacavam no cenário político e intelectual brasileiro, por exemplo, podemos citar aqueles que exerceram a presidência da entidade. Em seus quadros sociais circulavam políticos, profissionais liberais, empresários, jornalistas, intelectuais e funcionários do aparelho de Estado, os associados pertenciam a determinados círculos de sociabilidade que sem dúvida pesaram na sua adesão. As instituições culturais e científicas, como a Sociedade de Geografia do Rio de Janeiro, constituem uma estrutura elementar de sociabilidade. São lugares de fermentação da intelectualidade e também de relação afetiva. Ao mesmo tempo, viveiro e espaço de sociabilidade, a análise da sua atuação permite verificar o funcionamento da adesão e da exclusão de membros, fidelidades e influências exercidas, possíveis cisões e algumas tomadas de decisão.

Encabeça a lista de presidentes da entidade, José Lustosa da Cunha Paranaguá, o Marquês de Paranaguá, que permaneceu à frente da instituição desde a sua fundação até 1912, ano em que faleceu. Ocupou vários cargos políticos no governo imperial, seus laços familiares ainda nos indicam fortes relações de sociabilidade com as esferas do poder monárquico; era genro do Barão de Montserrat, Joaquim José Pinheiro de Vasconcellos que fora também presidente das províncias da Bahia e de Pernambuco. Suas filhas casaram-se com figuras de destaque do aparelho de Estado, tais como o doublé de político e escritor Franklin Menezes Dória, o Barão de Loreto, o desembargador Serafim Moniz Barreto e o diplomata Dominique Horace de Barral.

Logo após o seu desaparecimento, assumiu a presidência, entre 1912 e 1914, Francisco Marcondes Homem de Mello, o Barão Homem de Mello, então considerado como o primeiro cartógrafo brasileiro. Foi advogado, historiador, cartógrafo, político e professor do Colégio

29 SBG, "Cursos de aperfeiçoamento para professores de geografia do ciclo secundário". Revista da SBG, Rio de Janeiro, 1946, t. 53, p.74. 30 As modificações foram realizadas nos anos de 1886, 1910, 1918, 1924, 1936 e 1940.

180 - Cadernos do Desenvolvimento Fluminense, Rio de Janeiro, N.7, pp. 169 - 184, jan./jun. 2015 
Militar e da Escola Nacional de Belas Artes. Durante seis anos, entre 1914 e 1920, seria a vez de Marechal Gregório Thaumaturgo de Azevedo. A sua entrada na presidência inaugurava uma fase de sucessivos presidentes militares na entidade. O seu nome está associado à definição das fronteiras brasileiras com a Venezuela e a Bolívia. Em seguida, em 1920 e 1925, assumiu o ex-Ministro da Marinha Almirante Antônio Coutinho Gomes de Pereira. Depois deste, o General José Maria Moreira Guimarães ocupou o posto durante quinze anos até 1940, quando veio a falecer. Destacou-se como professor da Escola Politécnica, político e adido militar do Brasil no Japão durante a guerra entre a Rússia e o Japão entre 1904 e 1905. Seguido ao seu desaparecimento, assumiu o Almirante Raul Tavares entre 1940 e 1945, fechando temporariamente o ciclo de presidente-militares. Como estudante na Escola Naval, Raul Tavares envolvera-se na Revolta da Armada de 1893. Com o fim da sublevação, foi exilado no Chile, Argentina e Itália. Quando retornou ao Brasil em 1895, finalizou seus estudos e galgou carreira militar, sendo nomeado, posteriormente, Ministro do Supremo Tribunal Militar.

Em 1945, seria eleito o ex-chanceler José Carlos de Macedo Soares, que já ocupara a direção de outras entidades. ${ }^{31} \mathrm{Na}$ esfera diplomática, na qualidade de Ministro das Relações Exteriores, participou das negociações do Protocolo de 1935 que poria fim à Guerra do Chaco entre o Paraguai e a Bolívia, o que lhe garantiu o título de Chanceler da Paz, e em 1937 representaria o Brasil em Washington na posse do presidente Franklin D. Roosevelt. O exchanceler era um homem de governo, possuía excelentes relações com o Palácio do Catete, o que poderia facilitar o livre trânsito da Sociedade nas esferas de poder, iluminando-a publicamente.

Novamente, os militares ocupariam a presidência da instituição, após o breve período do chamado "movimento renovador" instituído por Macedo Soares. Viria o Almirante Jorge Dodsdworth Martins, entre 1951 e 1957, ex-Ministro da Marinha durante o governo de Gaspar Dutra. Seguido pelo General Francisco Jaguaribe Gomes de Mattos até 1960. Como militar e cartógrafo, Gomes de Mattos sobressaiu como integrante da chamada "Comissão Rondon”, a Comissão das Linhas Telegráficas Estratégicas de Mato Grosso ao Amazonas. Logo depois, o Almirante Washington Perry de Almeida ocupou o cargo até 1963, seguido pelo advogado, promotor militar e escritor Herbert Canabarro Reichardt. Após encerrar esta administração, em 1966, o engenheiro e geólogo, jornalista e deputado Jurandir de Castro Pires Ferreira assumiu a presidência até 1982, quando veio a falecer. Pires Ferreira destacouse como deputado federal, como diretor da Estrada de Ferro Central do Brasil e presidente do Instituto Brasileiro de Geografia e Estatística. Até recentemente, o cargo vinha sendo exercido pelo engenheiro, professor e ex-diretor da Estrada de Ferro Tereza Cristina de Santa Catarina, William Paulo Maciel.

\section{Considerações finais}

Desde a sua fundação até a transformação em Sociedade Brasileira de Geografia, em 1945, a Sociedade atuou como um lócus para o debate e a reunião de estudiosos da matéria.

31 Vale acrescentar que Macedo Soares também participou de outras associações científicas e culturais brasileiras e estrangeiras: Academia Internacional de Diplomacia, Ordem dos Advogados de São Paulo, Sociedade Brasileira de Antropologia e Etnografia, Liceu Literário Português, Academia Brasileira de Filologia e Academia Paulista de Letras, Instituto Histórico y Geográfico del Uruguai, Academia Uruguaya de Letras, Academia Argentina de Letras, Academia das Ciências de Lisboa, Real Academia de História de Portugal e Sociedade de Geografia de Lisboa, entre outras. 
As práticas científicas desenvolvidas, os empreendimentos acadêmicos realizados, do mesmo modo que o conhecimento acumulado na coleção das suas publicações, atestam que as iniciativas da Sociedade anteciparam-se ao conjunto de medidas tomadas na década de 1940, contribuindo para a formação da Geografia como um campo disciplinar autônomo no Brasil.

Podemos inferir que, a partir de 1945, começava uma nova fase para a Sociedade. Nos últimos anos, as transformações culturais, econômicas e políticas decorrentes das políticas públicas conduziriam a nação brasileira para um maior grau de complexidade. Tais medidas, ao lado da implementação de novos métodos, pesquisas e teorias, revigorariam a disciplina. As práticas geográficas até então desenvolvidas não se circunscreveriam aos antigos espaços, transferir-se-iam para as instituições oficiais, a exemplo da Associação dos Geógrafos do Brasil e do Instituto Brasileiro de Geografia e Estatística, ao lado dos cursos universitários.

Ao que parece não se tratava de um fato isolado ou exclusivo, situação análoga ocorreu na Sociedade de Geografia de Paris por volta de 1880 como demonstrou o geógrafo francês Lucien Gallois. Naquele período, foram organizados os cursos superiores nas universidades e a multiplicação de instituições similares. ${ }^{32}$ No caso brasileiro, ao mesmo tempo em que se pretendia ampliar a esfera de atuação da corporação para o âmbito nacional, ela se convertia em um espaço de consagração e de reconhecimento acadêmico. Apesar das mudanças em seus estatutos, a Sociedade permaneceria como entidade privada e como ambiente de congraçamento dos estudiosos da disciplina, fossem eles geógrafos com formação universitária ou diletantes.

\section{Referências bibliográficas}

ABREU, Martha Abreu; SOIHET, Rachel e CONTIJO, Rebeca (Orgs.), Cultura política e leituras do passado: historiografia e ensino de história. Rio de Janeiro: Civilização Brasileira, 2007.

ACADEMIA BRASILEIRA DE CIÊNCIAS. Anais da Academia Brasileira de Ciências. Rio de Janeiro, anos 1931-1934.

BERDOULAY, Vincent. La formation de l'École Française de Géographie (1870-1914). Paris: Bibliothèque Nationale, 1981.

BITTENCOURT, Agnello. Dicionário amazonense de biografias: vultos do passado. Rio de Janeiro: Edições Fundação Cultural do Amazonas, 1973.

BLACK, Jeremy. Mapas e história: construindo imagens do passado. São Paulo: EDUSC, 2005.

CARDOSO, Luciene P. Carris. O lugar da geografia brasileira: a Sociedade de Geografia do Rio de Janeiro entre 1883 e 1945. São Paulo: Annablume, 2013.

CAVENAGHI, Airton José. O território paulista na iconografia oitocentista: mapas, desenhos, fotografias. Análise de uma herança cotidiana. Anais do Museu Paulista, São Paulo: Universidade de São Paulo, vol. 14, n. 1, jun. 2006.

COELHO, Edmundo Campos. As profissões imperiais: Medicina, Engenharia e Advocacia no Rio de Janeiro, 1822-1930. Rio de Janeiro: Record, 1999.

32 Lucien Gallois (1857-1941) foi cofundador ao lado de Paul Vidal de La Blache dos Annales de Géographie em 1893. Sobre a institucionalização da Geografia na França, ver: Berdoulay (1981). 
DIACON, Todd A. Rondon: o marechal da floresta. São Paulo: Companhia das Letras, 1996. FERREIRA, Jorge Ferreira; DELGADO, Lucilia de A. Neves (Orgs.), O tempo do nacionalestatismo: do início da década de 1930 ao apogeu do Estado. Rio de Janeiro: Civilização Brasileira, 2003.

FRANCO, José Luiz de Andrade; DRUMMOND, José Augusto. Alberto José Sampaio: um botânico brasileiro e o seu programa de proteção à natureza. Varia História, n. 33, Minas Gerais, UFMG, 2005.

GOMES, Angela de Castro; OLIVEIRA, Lúcia Lippi; VELLOSO, Mônica Pimenta. Estado Novo: ideologia e poder. Rio de Janeiro: Zahar, 1982.

HOBSBAWN, Eric. A era dos extremos: o breve século XX (1914-1991). São Paulo: Companhia das Letras, 1995.

IHGB. Dicionário biobibliográfico de historiadores, geógrafos e antropólogos brasileiros; sócios falecidos entre 1881/1920; preparado por Vicente Tapajós com a colaboração de Pedro Tórtima. Rio de Janeiro: o Instituto, 1993.

MARTINS JUNIOR, Carlos. Apontamentos para uma leitura de Rondon e da Comissão de Linhas Telegráficas Estratégicas de Mato Grosso ao Amazonas. Tese de Doutorado. Programa de Pós-Graduação em História, Universidade de São Paulo, 2001.

MARY, Cristina Pessanha. Geografia Pátrias: Brasil e Portugal (1875-1889). Niterói: Editora da UFF, 2010.

MIYAMOTO, Shiguenoli. Geopolítica e poder no Brasil. São Paulo: Papirus, 1995.

MOTTA, Marly da Silva. 1922: em busca do Brasil moderno. Rio de Janeiro: CPDOC, 1994.

. O lugar da cidade do Rio de Janeiro na federação brasileira: uma questão em três momentos. Rio de Janeiro: CPDOC, 2001.

SBG, Coleção da Revista da Sociedade Brasileira de Geografia (1883-1948). Hemeroteca Digital da Biblioteca Nacional. Disponível em http://hemerotecadigital.bn.br.

SODRÉ, Nelson Werneck. História militar no Brasil. Rio de Janeiro: Civilização Brasileira, 1968.

copyright (C) @creative Cardoso 
